Journal of Management and Bussines (JOMB)

Volume 1, Nomor 2, Desember 2019

p-ISSN : 2656-8918

e-ISSN:2684-8317

DOI : https://doi.org/10.31539/jomb.v1i2.685

\title{
DAMPAK HUBUNGAN KARYAWAN DAN KEDISIPLINAN KERJA TERHADAP KINERJA KARYAWAN
}

\author{
Rizki Akbari $^{1}$, Kokom Komariah ${ }^{2}$, Dicky Jhoansyah ${ }^{3}$ \\ Universitas Muhammadiyah Sukabumi ${ }^{1,2,3}$ \\ rizkiakbary1@gmail.com ${ }^{1}$
}

\begin{abstract}
ABSTRAK
Tujuan penelitian ini adalah untuk mengetahui dampak hubungan karyawan (variabel X1) dan kedisiplinan Kerja (variabel X2) terhadap Kinerja Karyawan (variabel Y). Metode yang digunakan dalam penelitian ini yaitu menggunakan metode deskriptif dan metode asosiatif. Teknik pengumpulan data yang dilakukan peneliti dalam penelitian ini yaitu melalui observasi, wawancara angket, dokumentasi dan studi kepustakaan. Teknik analisis data yang digunakan adalah uji validitas, uji reliabilitas, analisis regresi linear berganda, termasuk uji koefisien determinasi dan koefisien korelasi ganda. Hasil penelitian uji koefisien determinasi dilihat dari nilai (Adjusted $\mathrm{R}^{2}$ ) sebesar 0,531 dapat diartikan bahwa dampak hubungan karyawan dan kedisiplinan keja terhadap kinerja karyawan adalah sebesar $53,1 \%$. Sisanya $46,9 \%$ dipengaruhi oleh faktor-faktor lain diluar penelitian ini. Simpulan, terjadi hubungan yang sedang antara hubungan karaywan dan kedisiplinan kerja dengan kinerja karyawan.
\end{abstract}

Kata Kunci: Hubungan Karyawan, Kedisiplinan Kerja, Kinerja Karyawan

\begin{abstract}
The purpose of this study was to determine the impact of employee relations (variable X1) and Work Discipline (variable X2) on Employee Performance (variable Y). The method used in this research is to use descriptive and associative methods. Data collection techniques used by researchers in this study are through observation, questionnaire interviews, documentation and literature studies. The data analysis technique used is the validity test, reliability test, multiple linear regression analysis, including the test of the coefficient of determination and multiple correlation coefficients. The results of the test of the coefficient of determination seen from the value (Adjusted R2) of 0.531 can be interpreted that the impact of employee relations and working discipline on employee performance is equal to 53.1\%. The remaining $46.9 \%$ is influenced by other factors outside this study. Conclusion, there is a moderate relationship between employee relations and work discipline with employee performance.
\end{abstract}

Keywords: Employee Relations, Work Discipline, Employee Performance 


\section{PENDAHULUAN}

Indonesia merupakan salah satu negara penghasil teh terbanyak di dunia, teh menjadi tanaman industri yang sangat penting dan pada saat ini teh menjadi salah satu minuman yang paling banyak di konsumsi di Indonesia maupun dunia, dari tanaman ini dapat diambil daunnya yang masih muda, kemudian diolah dengan baik untuk dijadikan minuman yang sehat dan nikmat. Teh ini bisa diolah menjadi berbagai macam minuman yang lezat sehingga pada zaman sekarang ini teh menjadi minuman yang didambakan karena bisa meningkatkan mood seseorang dan juga banyak orang berkreasi dengan teh sehingga makin banyak peminatnya. Selain rasanya yang sehat dan nikmat, teh juga di ekspor untuk menghasilkan devisa untuk Negara, tanaman teh ini berasal dari sub tropis jadi tanaman ini akan cocok ditanam di daerah pegunungan. Karena yang akan berpengaruh untuk pertumbuhan tanaman teh ini adalah kecocokan iklim dan tanah.

PTPN VIII Kebun Teh Goalpara yang beralamat di Jl.Goalpara km.8, Cisarua, Sukaraja, Kabupaten Sukabumi, Jawa Barat, merupakan salah satu unit kebun PT Perkebunan Nusantara VIII, yang berada di Provinsi Jawa Barat, Kecamatan Sukaraja, Sukabumi. Perusahaan ini didirikan dengan maksud dan tujuan untuk menyelenggarakan usaha di bidang agrobisnis dan agroindustri, untuk memanfaatkan sumber daya perseroan untuk menghasilkan barang atau jasa yang berkualitas tinggi dan berdaya saing kuat, serta mengejar keuntungan guna meningkatkan nilai perseroan dengan menerapkan prinsip-prinsip perseroan terbatas.

PTPN VIII Kebun Teh Goalpara Kabupaten Sukabumi merupakan salah satu Perkebunan Nusantara VIII yang ada di Sukabumi, dengan nomor Surat Izin Usaha Perkebunan ( SIUP ): 525/Kep.142 - Dishutbun/2010 yang merupakan salah satu perusahaan perkebunan dengan nama PTPN VIII Kebun Teh Goalpara yang beralamat di J1. Goalpara km 8, Desa Cisarua, Kecamatan Sukaraja, Kabupaten Sukabumi, Jawa Barat.

Berdasarkan hasil wawancara yang dilakukan dengan HRD pada PTPN VIII Kebun Teh Goalpara ditemukan permasalahan pada kinerja karyawan yang menurun selama tiga bulan terakhir, hal ini dapat dilihat dari menurunnya jumlah produk yang diolah tidak sesuai dengan target yang telah ditetapkan oleh perusahaan, yang membuktikan bahwa tidak tercapainya kinerja karyawan, efektivitas pekerjaan diduga 
menjadi permasalahan didalam kinerja karyawan diperusahaan, karena karyawan di bagian pengolahan dan teknik ini tidak menyelesaikan pekerjaannya tepat waktu.

Maka hal ini dapat dilihat dari tabel jumlah produk kering yang diolah yang terhitung dari bulan April 2018 sampai dengan Juni 2018, dengan data yang dapat dilihat di bawah ini:

Permasalahan tersebut diduga disebabkan oleh kurang baiknya hubungan karyawan didalam perusahaan, adapun hubungan karyawan yang kurang baik terjadi karena kurangnya kordinasi dan media komunikasi internal di perusahaan, sehingga penyampaian dan penerimaan informasi di dalam perusahaan tidak tersampaikan dengan baik.

Penyebab lainnya diduga disebabkan oleh kedisiplinan kerja karyawan di perusahaan yang kurang optimal karena karyawan masih ada yang melanggar peraturan kerja yang telah ditetapkan di perusahaan. Tujuan perusahaan sudah jelas tidak ingin karyawannya melakukan tindakan indispliner pada saat waktu bekerja, namun karyawan masih ada yang melanggar peraturan yang telah ditetapkan perusahaan, sehingga sering terjadi kesalahan dan keterlambatan pada saat bekerja terutama pada saat proses pengolahan didalam perusahaan, sehingga pekerjaan karyawan harus melebihi kapasitas dari jam kerja yang telah ditetapkan dan menjadikan suasana kerja di perusahaan pun menjadi kurang disiplin, maka dari itu permasalahan ini juga diduga berdampak pada tidak kinerja karyawan pada perusahaan.

\section{KAJIAN TEORI}

\section{Manajemen Sumber Daya Manusia}

Manajemen sumber daya manusia mempunyai peran utama bagi sebuah organisasi/ perusahaan karena manusia merupakan sumber utama dan penggerak dari seluruh aktivitas yang ada di dalam maupun diluar perusahaan. Dengan adanya sumber daya manusia yang berkualitas di dalam organisasi tentu akan lebih mudah mencapai tujuan yang telah ditetapkan oleh organisasi. Maka dari itu dengan pengelolaan manajemen sumber daya manusia yang baik di dalam organisasi tercapainya tujuan akan terlaksana dengan baik. Adapun pengertian manajemen sumber daya manusia menurut para ahli diantaranya sebagai berikut: 
Menurut Veithzal Rivai (2009) mendefinsikan "Manajemen sumber daya manusia adalah ilmu dan seni mengatur proses pendayagunaan sumber daya secara efisien, efektif dan produktif merupakan hal yang paling penting untuk tujuan perusahaan".

\section{Hubungan Karyawan}

Teori hubungan karyawan menurut Morissan (2010) "menyatakan salah satu bentuk dari komunikasi yang dapat dilakukan perusahaan kepada karyawannya adalah lewat bentuk kegiatan-kegiatan hubungan karyawan yang dilaksanakan pada perusahaan".

\section{Indikator Hubungan Karyawan}

Adapun untuk mengetahui hubungan karyawan, maka perlu diketahui kegiatan dimensi hubungan karyawan menggunakan teori dari (2010) yaitu: (1) Pendidikan dan pelatihan, yaitudilaksanakan perusahaan dalam upaya meningkatkan kinerja dan keterampilan skill karyawan, dan kualitas maupun kuantitas pemberian jasa pelayanan dan lain sebagainya (2) Motivasi kerja berprestasi,yaitu melalui pelatihan diharapkan dapat mempertemukan antara motivasi dan prestasi kerja serta disiplin karyawan dengan harapan-harapan atau kenginan dari pihak perusahaan dalam mencapai produktivitas tinggi (3) Program penghargaan,adalah upaya pihak perusahaan (pimpinan) dalam memberikan suatu penghargaan kepada karyawan, baik yang berprestasi kerja maupun cukup lama masa pengabdian pekerjaan. Dalam hal ini, penghargaan yang diberikan itu menimbulkan loyalitas dan rasa memiliki yang tinggi terhadap perusahaan (4) Program acara khusus (special event),suatu program khusus yang sengaja dirancang di luar bidang pekerjaan sehari-hari, misalnya dalam rangka event ulang tahun perusahaan diadakan kegiatan keagamaan, olahraga, lomba, hingga berpiknik bersama yang dihadiri oleh pimpinan dan semua para karyawannya. Kegiatan dan program tersebut dimaksudkan untuk menumbuhkan rasa keakraban bersama di antara sesama karyawan dan pimpinan (5) Media komunikasi internal, yaitu membentuk media komunikasi internal melalui buletin, news release (majalah dinding), dan majalah perusahaan yang berisikan pesan. Informasi dan berita yang berkaitan dengan kegiatan antar karyawan atau perusahaan dan pimpinan. 


\section{Kedisiplinan Kerja}

Sedangkan teori kedisiplinan kerja menurut Hasibuan (2013) pengertian disiplin kerja dapat diartikan kesadaran dan kesediaan seseorang mentaati peraturan perusahaan atau organisasi dan norma-norma sosial yang berlaku, dimana karyawan selalu datang dan pulang tepat waktu dan mengerjakan semua pekerjaannya dengan baik.

\section{Indikator Kedisiplinan Kerja}

Dimensi kedisiplinan kerja Menurut Hasibuan (2013) pada dasarnya banyak indikator yang mempengaruhi kedisiplinan kerja karyawan, diantaranya: (1) Tujuan dan Kemampuan, ikut mempengaruhi tingkat kedisiplinan karyawan. Tujuan yang akan dicapai jelas dan ditetapkan secara lokal serta cukup menantang kemampuan karyawan. Hal ini berarti tujuan (pekerjaan) yang dibebankan pada karyawan harus sesuai dengan kemampuan karyawan yang bersangkutan agar dia bekerja dengan sungguh-sungguh dan disiplin dalam menjalankannya (2) Teladan pemimpin, berperan dalam menentukan kedisiplinan karyawan karena pemimpin dijadikan teladan dan panutan oleh para bawahannya. Pimpinan harus memberi contoh yang baik, berdisiplin baik, jujur, adil, serta sesuai kata dengan perbuatannya, kedisiplinan bawahanpun ikut baik. Jika teladan pemimpin kurang baik, maka para karyawanpun akan kurang disiplin (3) Balas Jasa(gaji dan kesejahteraan), ikut mempengaruhi kedisiplinan karyawan karena balas jasa akan memberikan kepuasan kecintaan karyawan terhadap perusahaan atau pekerjaannya. Jika kecintaan karyawan semakin baik terhadap pekerjaan, kedisiplinan mereka akan semakin baik pula (4)Keadilan, keadilan ikut mendorong terwujudnya kedisiplinan karyawan, karena ego dan sifat manusia selalu merasa dirinya penting dan minta diperlakukan sama dengan manusia lainnya (5) Pengawasan Melekat ( Waskat), adalah tindakan nyata dan paling efektif dalam mewujudkan kedisiplinan karyawan perusahaan. Dengan waskat berarti atasan harus aktif dan langsung mengawasi perilaku, moral, sikap, gairah kerja, dan prestasi kerja karyawan dan karyawanpun merasa mendapat perhatian, bimbingan, petunjuk, pengarahan, dan pengawasan dari atasannya (6) Sanksi/Hukuman, berperan penting dalam memelihara kedisiplinan, dengan sanksi yang semakin berat karyawan akan semakin takut melanggar peraturan-peraturan perusahaan, sikap dan perilaku indisipliner (7) Ketegasan, memimpin dalam melakukan tindakan akan mempengaruhi kedisiplinan karyawan perusahaan. Pimpinan harus berani 
dan tegasan, bertindak untuk menghukum setiap karyawan yang indisipliner sesuai dengan sanksi hukuman yang diterapkan.

\section{Kinerja Karyawan}

Adapun teori mengenai kinerja karyawan menurut Mangkunegara (2006), "kinerja karyawan adalah hasil kerja secara kualitas dan kuantitas yang dicapai oleh seorang karyawan dalam melaksanakan tugasnya sesuai dengan tanggung jawab yang diberikan kepadanya".

\section{Indikator Kinerja Karyawan}

Untuk mengukur kinerja karyawan terdapat enam dimensi menurut Mathis dan Jackson (2010) yaitu: (1) Kuantitas keluaran, standar keluaran (output) lebih banyak digunakan untuk menilai prestasi karyawan di bagian produksi atau teknisi. (2) Efektivitas pekerjaan, suatu pekerjaan dikatakan efektif jika diselesaikan tepat pada waktunya sesuai dengan rencana.(3) Waktu keluaran, ketepatan waktu yang digunakan dalam menghasilkan sebuah barang sering digunakan sebagai ukuran atau penilaian terhadap prestasi kerja. (4) Tingkat kehadiran, jika kehadiran karyawan di bawah standar hari kerja yang ditetapkan maka karyawan tersebut tidak akan mampu memberikan kontribusi yang optimal terhadap organisasi. (5) Efisiensi pekerjaan, melakukan setiap kegiatan suatu organisasi dengan tujuan untuk dapat memperoleh hasil yang dikehendaki dengan usaha yang seminimal mungkin sesuai dengan standar yang ada. (6) Kualitas keluaran, jika yang digunakan dalam mengukur prestasi kerja karyawan itu.

Dalam suatu organisasi tercapainya tujuan organisasi itu tentu berdasarkan keberhasilan dari kinerja karyawan nya. Jika organisasi itu dapat membuat hubungan karyawan yang baik, harmonis, tepat dalam penerimaan dan penyampaian informasi serta suasana kerja yang disiplin di perusahaan sehingga menumbuhkan kualitas kinerja yang optimal dapat mengerjakan tugas dan tanggung jawabnya dengan baik.

Maka beberapa faktor diatas saling memiliki dampak dari sikap karyawan dalam bekerja yang kemudian berdampak pada kinerja karyawan. Maka dari itu, dalam penelitian ini penting disampaikannya anggapan dasar yaitu: 


\section{METODE PENELITIAN}

Variabel dalam penelitian terdiri dari variabel independen yaitu hubungan karyawan (X1) dan kedisiplinan kerja (X2) serta variabel dependen yaitu kinerja karyawan (Y). Metode penelitian yang dipakai ialah deskriptif dan asosiatif. Paradigma penelitian menggunakan paradigma ganda dengan dua variabel independen.

Teknik pengumpulan data menggunakan observasi, wawancara, angket, dokumentasi dan studi kepustakaan. Teknik analisa data menggunakan koefisien korelasi ganda untuk mengukur hubungan antar variabel, koefisien determinasi untuk mengukur besarnya pengaruh variabel hubungan karyawan dan variabelkedisiplinan kerja terhadap kinerja karyawan, analisis regresi berganda untuk mengukur konsistensi nilai variabel terikat dan uji $\mathrm{F}$ untuk menguji hipotesis.

Adapun populasi dalam penelitian ini adalah 72 karyawan PTPN VIII Kebun Teh Goalpara Kabupaten Sukabumi pada bagian teknik dan produksi. Teknik pengambilan sampel yang digunakan oleh peneliti adalah teknik sampling jenuhyang semua anggota populasi dugunakan sebagai sampel. Penelitian ini menggunakan uji validitas dengan rumus product moment dan uji reliabilitas dengan rumus cronbach's alpha. Angket yang disebar menggunakan skala Likert dengan pernyataan positif.

\section{HASIL PENELITIAN}

\section{Hasil Analisis Regresi Linear Berganda}

Tabel 1 Hasil Uji Linier Berganda

\begin{tabular}{|c|c|c|c|c|c|}
\hline \multicolumn{6}{|c|}{ Coefficients $^{\mathrm{a}}$} \\
\hline \multirow[b]{2}{*}{ Model } & \multicolumn{2}{|c|}{ Unstandardized Coefficients } & \multirow{2}{*}{$\begin{array}{c}\text { Standardized Coefficients } \\
\text { Beta }\end{array}$} & \multirow[b]{2}{*}{$\mathrm{t}$} & \multirow[b]{2}{*}{ Sig. } \\
\hline & B & Std. Error & & & \\
\hline $\begin{array}{ll}1 & \text { (Constant })\end{array}$ & 7.515 & 1.501 & & 5.007 & .000 \\
\hline Hubungan & .252 & .111 & .270 & 2.273 & .026 \\
\hline karyawan & & & & & \\
\hline $\begin{array}{l}\text { Kedisiplinan } \\
\text { kerja }\end{array}$ & .380 & .087 & .517 & 4.356 & .000 \\
\hline a. Dependent Var & Kinerja & awan & & & \\
\hline
\end{tabular}

Tabel 1 diatas menjelaskan dari output uji regresi linier berganda diatas, maka dapat diperoleh persamaan bagaimana dijelaskan berikut ini: $\mathrm{Y}=7.515+0,252 \mathrm{X}_{1}+0,380 \mathrm{X}_{2}$ 
Tabel 2 Hubungan Karyawan dan Kedisiplinan Kerja

\begin{tabular}{llrccc}
\multicolumn{5}{c}{ Model Summary } \\
\hline Model & R & R Square & $\begin{array}{c}\text { Adjusted R } \\
\text { Square }\end{array}$ & $\begin{array}{c}\text { Std. Error of the } \\
\text { Estimate }\end{array}$ \\
\hline 1 & $.738^{\mathrm{a}}$ & .545 & .531 & 1.56033
\end{tabular}

a. Predictors: (Constant), Kedisiplinan kerja, Hubungan karyawan Sumber: data primer (kuisioner) 2019

Hasil tabel 2 diatas model summary besarnya adjusted $\mathrm{R}^{2}$ yaitu 0,531 ; hal ini berarti 53,1\% variasi kinerja karyawan dapat dijelaskan oleh variasi dari dua variabel independen. Hubungan karyawan dan Kedisiplinan kerja sedangkan sisanya $46,9 \%(100 \%-53,1 \%=46.9 \%)$ dari faktor yang tidak diteliti.

\section{Koefisien korelasi Ganda (R)}

Tabel 3 Hasil Koefisien Korelasi Ganda

\begin{tabular}{ll|r|rr} 
& \multicolumn{3}{c}{ Model Summary } \\
Model & R & R Square & Adjusted R Square & Std. Error of the Estimate \\
\hline 1 & $.738^{\mathrm{a}}$ & .545 & .531 & 1.56033 \\
\hline a. Predictors: (Constant), Kedisiplinan kerja, Hubungan karyawan & \\
Sumber: data primer (kuisioner) 2019 &
\end{tabular}

Berdasarkan tabel 3 di atas dipeoleh angka R sebesar 0,738 berada pada katagori kuat. Hal ini menunjukan bahwa terjadi hubungan yang sedang antara Hubungan karyawan dan Kedisiplinan kerja dengan kinerja karyawan.

\section{Uji Signifikan Secara Simultan (Uji F)}

\section{Tabel 4 Hasil Uji F}

\begin{tabular}{|c|c|c|c|c|c|c|}
\hline \multicolumn{7}{|c|}{ ANOVA $^{\mathrm{a}}$} \\
\hline \multicolumn{2}{|c|}{ Model } & Sum of Squares & Df & Mean Square & $\mathbf{F}$ & Sig. \\
\hline \multirow[t]{3}{*}{1} & Regression & 200.886 & 2 & 100.443 & 41.256 & $.000^{\mathrm{b}}$ \\
\hline & Residual & 167.989 & 69 & 2.435 & & \\
\hline & Total & 368.875 & 71 & & & \\
\hline
\end{tabular}

Tabel 4 menjelaskan Uji $\mathrm{F}$ variabel $\mathrm{X}_{1}$ (Hubungan karyawan) $\mathrm{X}_{2}$ (Kedisiplinan kerja) dan Y (Kinerja karyawan) adalah sebesar 41.256 dapat di peroleh dari nilai sig. 
$0,000<0,05$; nilai $F_{\text {hitung }} 41.256>F_{\text {tabel }} 3,13$. Artinya bahwa hubungan karyawan dan kedisiplinan kerja berpengaruh secara simultan terhadap kinerja karyawan.

Tabel 5 Jumlah Skor Tanggapan Responden Mengenai Variabel Hubungan Karyawan

\begin{tabular}{clc}
\hline No & \multicolumn{1}{c}{ Pernyataan } & Skor \\
\hline 1 & $\begin{array}{l}\text { Perusahaanberupaya untuk meningkatkan kinerja dan keterampilan } \\
\text { karyawan di perusahaan. } \\
2\end{array}$ & $\begin{array}{l}\text { Adanya motivasi dan pelatihan untuk mencapai produktivitas tinggi di } \\
\text { perusahaan. }\end{array}$ \\
3 & $\begin{array}{l}\text { Adanya upaya dari perusahaan memberikan suatu penghargaan kepada } \\
\text { karyawan. }\end{array}$ \\
4 & $\begin{array}{l}\text { Adanya suatu program acara khusus (special event)dari perusahaan untuk } \\
\text { menumbuhkan rasa keakraban diantara sesama karyawan. }\end{array}$ \\
5 & $\begin{array}{l}\text { Adanya media komunikasi internal yang baik berhubungan dengan } \\
\text { penyampaian dan penerimaanberita informasi dan kegiatan di } \\
\text { perusahaan. }\end{array}$ & 254 \\
\hline & \multicolumn{1}{c}{ Total } \\
\hline
\end{tabular}

Sumber: Hasil pengolahan data kuisioner, 2019

Secara keseluruhan, berdasarkan perhitungan pengkategorian data yang didapatkan bahwa nilai hubungan karyawan sebesar 1.252 berada diantara kriteria sedang dan tinggi. Hal ini menunjukan bahwa hubungan karyawanyang kurang baik yang terjadi pada PTPN VIII Kebun Teh Goal para sudah cukup tinggi. Hal ini diartikan bahwa hubungan karyawan yang terjadi di perusahaan kurang baik tetapi masih bisa teratasi. Hal ini harus diperhatikan dan sebagai bahan evaluasi bagi perusahaan agar hubungan karyawan yang kurang baik dialami karyawan tidak semakin tinggi. Hubungan karyawan yang kurang baik akan mengakibatkan komunikasi dan kinerja karyawan di perusahaan akan semakin menurun. Hal ini akan menyebabkan perusahaan kesulitan dalam mencapai apa yang menjadi tujuan mereka.

Tabel 6 Jumlah Skor Tanggapan Responden Mengenai Variabel Kedisiplinan Kerja

\begin{tabular}{clc}
\hline No & \multicolumn{1}{c}{ Pernyataan } & Skor \\
\hline 1 & $\begin{array}{l}\text { Tujuan (pekerjaan) yang diberikan perusahaan kepada karyawan sesuai } \\
\text { dengan kemampuan karyawan. }\end{array}$ & 260 \\
2 & $\begin{array}{l}\text { Pimpinan perusahaan bersikap disiplin yang menjadikan teladan } \\
\text { kedisiplinan di perusahaan. }\end{array}$ & 247 \\
3 & $\begin{array}{l}\text { Balas jasa (upah dan kesejahteraan) sesuai dengan apa yang telah } \\
\text { dikerjakan. }\end{array}$ & 244 \\
4 & $\begin{array}{l}\text { Adanya perlakuan yang adil terhadap sesama karyawan di perusahaan. } \\
5\end{array}$ & $\begin{array}{l}\text { Adanya tindakan pengawasan kedisiplinan secara nyata di dalam } \\
\text { kegiatan perusahaan. }\end{array}$ \\
\hline
\end{tabular}




\begin{tabular}{clc}
\hline 6 & $\begin{array}{l}\text { Adanya peraturan kerja perusahaan mengenai sikap dan perilaku yang } \\
\text { indisipliner. }\end{array}$ & 239 \\
7 & Pimpinan tegas dalam melakukan tindakan kedisiplinan di perusahaan. & 248 \\
\hline & Total & $\mathbf{1 . 7 3 2}$ \\
\hline
\end{tabular}

Sumber: Hasil pengolahan data kuesioner 2019

Secara keseluruhan, berdasarkan perhitungan pengkategorian data yang didapatkan bahwa nilai kedisiplinan kerja sebesar 1.732 berada diantara kriteria sedang dan tinggi. Hal ini menunjukan bahwa kedisiplinan kerjayang yang terjadi pada PTPN VIII Kebun Teh Goalparasudah cukup tinggi. Hal ini diartikan bahwa kedisiplinan kerja yang terjadi di perusahaan kurang baik, tetapi ini masih bisa teratasi. Sehingga ini harus diperhatikan dan sebagai bahan evaluasi bagi perusahaan agar kedisiplinan kerja yang kurang baikpada karyawan ini tidak semakin tinggi. Kedisiplinan kerja yang kurang baik akan mengakibatkan tingkat kedisiplinan dan kinerja karyawan di perusahaan akan semakin menurun. Sehingga ini akan menyebabkan perusahaan kesulitan dalam mencapai apa yang menjadi tujuan dan target mereka.

Tabel 7 Jumlah Skor Tanggapan Responden Mengenai VariabelKinerja Karyawan

\begin{tabular}{clc}
\hline No & \multicolumn{1}{c}{ Pernyataan } & Skor \\
\hline 1 & $\begin{array}{l}\text { Karyawanmencapai standar keluaran untuk penilaian prestasi karyawan } \\
\text { di bagian pengolahan dan teknik di perusahaan }\end{array}$ & 253 \\
2 & $\begin{array}{l}\text { Karyawan selalu meyelesaikan pekerjaan tepat waktu agar sesuai dengan } \\
\text { rencana. }\end{array}$ & 248 \\
3 & $\begin{array}{l}\text { Karyawan tepat waktu dalam menghasilkan produk di perusahaan. } \\
4\end{array}$ & 250 \\
5 & $\begin{array}{l}\text { Karyawan selalu hadir pada saat jam kerja. } \\
\text { tujuan memperoleh hasilsesuai yang dikehendaki. }\end{array}$ & 251 \\
6 & $\begin{array}{l}\text { Karyawan puas dengan cara perusahaan mengukur prestasi kerja } \\
\text { karyawan. }\end{array}$ & 252 \\
\hline & $\quad$ Total & $\mathbf{1 . 5 1 3}$ \\
\hline
\end{tabular}

Sumber: Hasil pengolahan data kuesioner 2019

Secara keseluruhan, berdasarkan perhitungan pengkategorian data yang didapatkan bahwa nilai kinerja karyawan sebesar 1.513 berada diantara kriteria sedang dan tinggi. Hal ini menunjukan bahwa kinerja karyawan pada PTPN VIII Kebun Teh Goalpara tergolong tinggi.Hal ini dapat diartikan bahwa kinerja karyawan pada 
perusahaan terbilang kurang baik. Hal ini harus di evaluasi dan ditingkatkan oleh perusahaan guna kemajuan dan kelangsungan hidup perusahaan yang lebih baik. Jika kinerja karyawan terus menurun tentu perusahaan pun akan sulit mencapai tujuannya. Hal ini dilihat dari tanggapan responden mengenai kinerja karyawan, sumber daya manusia pada PTPN VIII Kebun Teh Goalparamasih kurang baik untuk menunjang perusahaan dalam mencapai tujuannya.

\section{PEMBAHASAN}

\section{Pengaruh Hubungan Karyawan terhadap Kinerja Karyawan}

Diketahui bahwa variabel memiliki pengaruh yang signifikan terhadap kinerja karyawan di PTPN Kebun Teh Goalpara Kabupaten Sukabumi. Dapat dilihat dari tanggapan responden yang kurang baik terhadap hubungan karyawan yang terjadi di perusahaan, sehingga koordinasi dan komunikasi di perusahaan tidak berjalan dengan baik. Sebagaimana yang diungkapkan oleh Morissan (2010) "menyatakan salah satu bentuk dari komunikasi yang dapat dilakukan perusahaan kepada karyawannya adalah lewat bentuk kegiatan-kegiatan hubungan karyawan yang dilaksanakan pada perusahaan". Dari hasil penelitian yang dilakukan oleh peneliti terdahulu yaitu Sri Limanti Yulianti Ningsih (2009) penelitian sebelumnya sejalan dengan yang dilakukan saat ini bahwa variabel hubungan karyawan berpengaruh terhadap kinerja karyawan di PTPN VIII Kebun Teh Goalpara Kabupaten Sukabumi.

\section{Pengaruh Kedisiplinan Kerja terhadap Kinerja Karyawan}

Diketahui bahwa variabel memiliki pengaruh yang signifikan terhadap kinerja karyawan di PTPN Kebun Teh Goalpara Kabupaten Sukabumi. Dapat dilihat dari tanggapan responden yang kurang baik terhadap kedisiplinan kerja yang terjadi di perusahaan, sehingga kedisiplinan kerja karyawan diperusahaan berjalan tidak sesuai dengan aturan yaitu tidak berjalan dengan baik. Sebagaimana diungkapkan Hasibuan (2013) disiplin kerja dapat diartikan kesadaran dan kesediaan seseorang mentaati peraturan perusahaan atau organisasi dan norma-norma sosial yang berlaku, dimana karyawan selalu datang dan pulang tepat waktu dan mengerjakan semua pekerjaannya dengan baik. Dari hasil penelitian yang dilakukan oleh peneliti terdahulu yaitu Nur Avni Rozalia (2015) penelitian sebelumnya sejalan dengan yang dilakukan saat ini bahwa 
variabel kedisiplinan kerja berpengaruh terhadap kinerja karyawan di PTPN VIII Kebun Teh Goalpara Kabupaten Sukabumi.

\section{SIMPULAN}

Penilitian ini bertujuan untuk menganalisis damapak hubungan karyawan dan kedisiplinan kerja terhadap kinerja karyawan. Dan dengan mengetahui hubungan karyawan dan kedisiplinan kerja yang terjadi diperusahaan ini, diharapkan dapat mengetahui faktor yang mempengaruhi dari kinerja karyawan dan memberikan hasil jangka panjang. Berdasarkan dari hasil analisis yang telah dilakukan, maka dapat disimpulkan bahwa dari hipotesis menunjukkan bahwa hubungan karyawan dan kedisiplinan kerja berpengaruh terhadap kinerja karyawan. Dalam arti semakin baik hubungan karyawan yang terjadi di dalam perusahaan maka kinerja dari karyawan diperusahaan akan baik atau tinggi dan semakin baik kedisiplinan kerja dari karyawan juga akan semakin baik dalam menyelesaikan tugasnya. Hasil analisis ini menunjukkan bahwa hubungan karyawan dan kedisiplinan kerja berpengaruh terhadap kinerja karyawan.

\section{DAFTAR PUSTAKA}

Hasibuan, M. (2013). Manajemen Sumber Daya Manusia. Jakarta: Bumi Aksara

Mangkunegara, M., Prabu, A. (2006). Evaluasi Kinerja Sumber Daya Manusia. Bandung: Refika Aditama

Mathis, L. R., Jackson, J. H. (2010). Human Resource Management. 13th Edition. South Western: Joseph Sabatino

Morissan, M. (2010). Manajemen Public Relations. Jakarta: Prenada Media Group

Ningsih, Sri L. Y. (2009). Strategi Employee Relations Untuk Meningkatkan Kinerja Karyawan Dan Citra Pada PT Kereta Api (Persereo). Jurnal Ilmu Komunikasi UPNYK, 7(2)

Rivai, V. (2009). Manajemen Sumber Daya Manusia untuk Perusahaan Dari Teori ke Praktik. Jakarta: Raja Grafindo Persada

Rozalia, N. A. (2015). Pengaruh Motivasi Kerja dan Disiplin Kerja terhadap Kinerja Karyawan (Studi Kasus pada karyawan PT.Pattindo Malang). Jurnal Administrasi Bisnis, 26(2), 1-8

Ruslan, R. (2002). Manajemen Humas dan Komunikasi, Konsepsi dan Aplikasi.Jakarta: Grafindo Persada

Ruslan, R. (2010). Manajemen Publik Relations \& Media Komunikasi, Konsep \& Aplikasinya. Jakarta: PT. Rajagrafindo Persada 